\title{
The Impact of Social Media Technologies on Adult Learning
}

\author{
Khalil Alsaadat \\ Department of Educational Policies, College of Education, King Saud University, Saudi Arabia
}

\begin{tabular}{l} 
Article Info \\
\hline Article history: \\
Received Sep 9, 2017 \\
Revised Apr 15, 2018 \\
Accepted Apr 23, 2018 \\
\hline
\end{tabular}

Keyword:

Adult learners

Social media

Technology

\begin{abstract}
Technology and social media have presented significant tools for adult learners to learn and advance continually. Fast technological advancements have enabled development of technologies used for learning. Expansion of various tools has given professors, educaters, trainers, instructers, many alternatives towards the implementation of the technology supported learning. The use of social media can improve adult learning outcomes and academic accomplishment. Social media is increasingly proven to be beneficial in adult learning and has a huge potential for adult education. This paper sheds some lights on benefits of social media for adult learners, this is incorporated through the review of previous work and some barriers that encounters social media for learning purposes. Also some social media models are reviewed to show the growth and effect of social media in adult learning context, and suggestions and recommendations are provided.
\end{abstract}

Copyright $\odot 2018$ Institute of Advanced Engineering and Science. All rights reserved.

\section{Corresponding Author:}

Khalil Alsaadat,

Department of Educational Policies,

College of Education,

King Saud University, Saudi Arabia.

Email: alsaadat@gmail.com

\section{INTRODUCTION}

The advent of Web 2.0 and the spread of social software tools have created new and exciting opportunities for designers of digitally-mediated education programs for adults. Whether working in fully online, blended, or face-to-face learning contexts, instructors may now access technologies that allow students and faculty to engage in cooperative and collaborative learning despite being separated in space and time. By supporting the use of interactive methods and multi-media materials, social software offers educators more ways to engage learners than any preceding educational technology. Social software also empowers curriculum designers to more effectively accommodate many of the core principles of adult learning than was possible with earlier e-learning technologies (Lenoue et al., 2011) [1]. Social media is increasingly becoming an essential platform for social connectivity in our daily lives. The availability of mobile technology has further fueled its importance making it a ubiquitous tool for social interaction [2].

With the rapid growth of the Internet and the World Wide Web, online learning is becoming an increasingly important mode of education, which allows learners to participate regardless of geographic location, independent of time and place Shen, et al., 2017 said they continue that There are numerous names for online learning activities such as e learning, web based learning and training, Internet based training, distributed learning, digital collaboration, and distance learning. In online learning environments, social negotiation and collaboration are supported through the use of document sharing tools and groupware as well as asynchronous and synchronous communication technology. Recent development of communication technology, especially mobile communication technology, facilitate students' engagement in online education and lead to the emerging of mobile social media learning (Shen et al., 2017) [3].Social media technology provides educators with an opportunity to engage learners in the online classroom, as well as to support development of learner skills and competencies[4]. 
Norman et al., (2015) think that Social media is becoming a ubiquitous platform for social interaction in our daily lives. The explosion of social media has led to numerous research by educators to tap and seek into the potential of social media for learning. Although adult learners are constantly on the move, social media allows them to stay connected to their peers in digital social interaction spaces via mobile devices. The connectivity of mobile learners that learn using social media on mobile devices is termed, mobile social media learning. Mobile social media learning is changing the way we understand the term participation in a learning community. Although much work has been done in understanding participation in social media, fewer studies have focused on investigating participation of learning in mobile social media where learners are mobile and use social media on mobile device [2].

\section{RELATED STUDY}

a. Feldman study (2015)

This paper provides a resource on the impact of social media on adult learners' construction of knowledge, particularly as it pertains to adult education's role in fostering a robust democratic society. There has been an increase in the literature in recent years that explores the various aspects of social media use, such as the incivility of online discussion, the homogenous nature of views learners are exposed to online, and the ability of individual and corporate actors to manipulate online content. This paper aims to provide a wide angle view of the situation while achieving two goals (a) development of categories which group implications of social media use (b) argument of low social media information literacy as a challenge facing adult educators [5].

b. Norman, et al., study (2015)

This study investigated roles of social participation in mobile social media learning using the "ladder of participation and mastering." Participants were students taking an educational technology course in a local university. The study was conducted in a four-month period. Data was collected from discussions while learning among the students a social media platform, Facebook groups, on mobile devices. The data was analyzed using a social network analysis tool, NodeXL. Data was analyzed based on egocentric networks, betweeness centrality, and closeness centrality. The findings revealed that there are four roles of social participation in mobile social media, which are: lurkers; gradually mastering members/passive members; recognized members; and coaches. The findings also indicated that over the course of four months, learners can interchange roles of social participation becoming more central or less central in learning discussions. As a result a roles of participation ontinuum for mobile social media learning is proposed. Future research could be conducted in other fields to investigate whether the continuum produced could be used to understand the relationship between mobile social media learning and social participation roles [2].

c. Green and Lewin (2016)

Green and Lewin argued that social media has the potential to bridge formal and informal learning through participatory digital cultures. Exemplars of sophisticated use by young people support this claim, although the majority of young people adopt the role of consumers rather than full participants. Scholars have suggested the potential of social media for integrating formal and informal learning, yet this work is commonly under-theorized. They propose a model theorizing social media as a space for learning with varying attributes of formality and informality. Through two contrasting case studies, they apply their model together with social constructivism and connectivism as theoretical lenses through which to tease out the complexities of learning in various settings. They conclude that their model could reveal new understandings of social media in education, and outline future research directions [6].

d. Kear et al., study (2016)

In this study three exemplars are presented of social technologies deployed in educational contexts: wikis; a photo-sharing environment; and a social bookmarking tool. Students were found to engage with the technologies selectively, sometimes rejecting them, in the light of their prior conceptions of education. Some students (a minority in all the studies) were unsympathetic to the educational philosophy underpinning the technology's adoption. The paper demonstrates, through an examination of in-context use, the importance of sociocultural factors in relation to education, and the non-deterministic nature of educational technology. The academic study of technology has increasingly called into question the deterministic views which are so pervasive in popular discourse and among policy-makers. Instead, sociocultural factors play a crucial role in shaping and defining technology and educational technology is no exception, as the examples in the paper show. The paper concludes by drawing out some implications of the examples for the use of social technologies in education [7]. 
e. Gülbahar et al., study (2017)

While ubiquitous in everyday use, in reality, social media usage within higher education teaching has expanded quite slowly. Analysis of social media usage of students and instructors for teaching, learning, and research purposes across four countries (Russia, Turkey, Germany, and Switzerland) showed that many higher education instructors actively use social media for private purposes. However, although they understand that their students also use it for learning purposes, and instructors sense the potential of social media in teaching, they mostly refrain from doing so due to various barriers. In response, an openly accessible trilingual social media toolkit was developed which analyzes the teaching scenario with several questions, before suggesting, based on an algorithm, the best matching class of social media, complete with advice on how to use it for teaching purposes. This study explains the rationale behind the toolkit, its development process, and examines instructors' perceptions towards it [8].

f. Shen et al., study (2017)

Educational practitioners have adopted social media to their online or mobile communities, little attention has been paid to investigate the social media messages related to online or mobile learning. The purpose of this study is to identify social media influencers and trends by mining Twitter posts related to online learning and mobile learning. They identified the influencers on Twitter by three different measures: the number of tweets posted by each user, the number of mentions by other users for each user, and the number of retweets for each user. They also analyzed the trends of online learning and mobile learning by the following perspectives: the descriptive statistics of the related tweets, the monthly and hourly line charts of the related tweets, the descriptive statistics of the related retweets, the volume trends of the most retweeted tweets, and the top 10 hash tags of the related tweets. The results of this study can provide educational practitioners different ways of understanding and explaining the public opinions toward online learning and mobile learning [3].

The previous studies showed that today, practitioners increasingly realize that opportunities for growth, development, and innovation lie outside their own organization. These and recent other technological developments have given rise to more openness in organizational practices. This openness makes employees less constrained by boundaries that otherwise would impede knowledge sharing. Current technologies and use of social media enable professionals to connect with their peers with greater ease, at a larger scale and on a continuing basis (Scherurs et al., 2014) [9]. Shen et al., (2017) argued that, over the past decade, online social networking sites such as Facebook ,mobile phones twitter and others are one of the communications technologies that have been widely adopted by adult learners (Shen et al., 2017) [3]. The social impact and the quality of information through Facebook had a positive impact both directly and indirectly in determining the sustainability of one's intention in the learning process [10-berlilana]. Educational practitioners have also adopted social networking tools to online learning communities for their course design and delivery. By connecting mobile learning to social media sites, learners can get the necessary contextual information from the other users. Social networking technologies, and media can foster interaction and communication between learners and instructors, because learners may have limited face to face time to build a support network with their peers in online or mobile learning environments. The bridge on social media plays an important part in learners motivation, retention, and learning in distributed learning environments [3].

\section{CHALLENGES OF SOCIAL MEDIA}

Many of the positives of deploying social media in digital education, have also been challenged, Salmon et al., (2015), reviewed some studies concerning the challenges social media encounters as a learning tool. They reported that some studies highlighted that there is no adequate evidence that social networks provide an arena for all students to develop critical and independent thinking skills. Other studies show that students feel that social media reduces student collaboration because students work separately on different parts of a project, which minimises opportunities for collaborative learning. Students also report that using social media in learning may lead to misunderstandings, less knowledge sharing, and less creative thinking. Furthermore, the quality and accuracy of the information shared in collaborative social media spaces varies greatly. Some students report seeing the use of social media such as Face book as time wasting or a form of procrastination studies such as Madge (2009), argues that students are not keen to use Facebook for formal discussions relating to teaching and learning, or to liaise with instructors. Students may feel that using social media in education distorts the boundaries between their online social and educational worlds, between social and informal and formal spaces, and between public and private spaces. Both students and academics may feel that social media for educational purposes interferes with their private lives, which raises concerns about representing identities in the online environment [11]. Gulbahar et al., (2017), reviewed different studies concerning the barriers of social media as a learning tool. 
They found that various studies have shown that the latter caused greater challenges to technology integration than the former. Additionally, Hew and Brush (2012), analyzed literature published from 1995 to 2006 and identified: resources, knowledge/skills of teachers, and attitudes and beliefs as the most frequently cited barriers. However, the major obstacle stated was a lack of knowledge, second order barrier, and skills of how to effectively integrate social media from an instructional design perspective. Rogers Estable (2014) researched extrinsic and intrinsic faculty barriers to the adoption of Web 2.0 technologies and reported the top four obstacles as: No training on usage, No time to learn how to use, Lack of administrative support, and No technology support. Gulbahar et al., (2017) also reported some barriers in their study. Instructors are both enthusiastic and skeptical about integrating social media within teaching and have pedagogical concerns about quality and student success. Instructors stated a need for a roadmap on what to do, how to do it, and where to start. They lack relevant information on the process and are progressing only through self-motivated individual effort. they concluded that social media offers potential, but also poses barriers to achieving the goal of supporting instructors tapping the potential offered by social media in higher and adult education. Barriers are related to the skills and needs of teachers, whereas potential is more applicable for learners. Therefore, it can be said that solutions should be provided to support teachers overcoming possible barriers to effective social media integration in higher and continuing education [8]. However in spite of these barriers Through social online interaction and discussion adult learners collaboratively share messages not only relating to their tasks and concerns that they may have about that task, but also their own strategies on how a specific task can be solved and completed. Online learning environment that uses social networking can help establishing online connections and minimize isolation feelings, which usually occur in online learning where adult learners feel isolated or lonely [12].

\section{SOCIAL MEDIA LEARNING MODELS}

a. Park (2011) frame work

Park conducted a study to review and classify a variety of educational applications with mobile technologies. He generated a conceptual and pedagogical framework that was based on high versus low transactional distance and individualized versus socialized activity. The four types of mobile learning generated in the context of distance education include high transactional distance socialized $\mathrm{m}$ learning, high transactional distance individualized m-learning, low transactional distance socialized m-learning, and low transactional distance individualized mobile learning [13].

b. Sathick and Venka (2015) frame work

This framework aims to provide a personalized and non personalized recommendation system for the web user with the help of common data repository. The proposed framework shows the typical interaction between the user and the web through the knowledge engine which acts as a logical interface for the user to fetch useful information from the web.

The work carried out in this research study is emphasized through the following components: managing data repository, knowledge engine query processor component, and establishment of online recommendation system. An experimental methodology was adopted to generate a user interface where a user enters his web based queries which targets the performance analysis of a student for his career guidance and the solution obtained in this study provides a suitable recommendation system for the student in terms of providing him suitable career guidance. The main goal is to improve quality and standard of interaction among the web community [14].

c. Thomas and Woodside (2016) model

Thomas and woodside proposed a social media maturity model which healthcare organizations can use as a management tool to understand their position and capabilities and to plan for improvements. This model can also be used to determine the state of the industry, and to identify leaders and laggards. At the broadest level, the building blocks of social media maturity can be stated as follows:

$$
\text { Social media maturity: Content }+ \text { Community }+ \text { Integration }=\text { Coherence }
$$

Within each of the social media maturity components, several subcomponents are identified. They proposed that these subcomponents are basic indicators for determining an organization's level of knowledge and sophistication in terms of content, community, and integration, or its social media maturity [15]. 
d. Gulbahar et al., (2017) social media toolkit

Gulbahar et al., (2017) designed a social media model which they called a social media toolkit designed as a guide for instructors wanting to effectively integrate social media within their courses. Employing universal terminology, geographic variations, Russia, Turkey, Germany, and Switzerland, various cultures, disciplines, and diverse requirements were addressed in order to ensure uniform comprehension of concepts by all instructors users. The toolkit was designed to be straightforward and uncomplicated, preventing the sort of misunderstandings revealed from their research and as found in the literature. The following is the Framework for the Social Media Toolkit as it was reported in their study:

1. Instructional methods

Six well-known approaches to teaching Presentation Model, Training Model, Concept Teaching, Cooperative Learning Model, Problem Based Learning, Holding Discussion, three of which are teacher centered and three student centered, were the instructional methods selected due to their common usage.

Instructional method is important for instructional design and the selection of any corresponding social media tool. To ensure effective guidance, the toolkit employs instructional methods together with detailed explanations, including phases of implementation and a general summary.

2. Knowledge levels

The second dimension of the framework, knowledge levels, refers to learning goals based on the cognitive dimension of Bloom's revised taxonomy, the strong theoretical framework used both by educators and researchers.

Explanation of each knowledge level, sample assessment types, and activities are provided separately to increase user understanding. Instructors can read explanations of each knowledge level, or review sample activities in order to determine the knowledge level the instructor wants students to achieve. Based on these findings, plus three other domains instructional models, assessment, content, the most suitable social media is suggested, allowing instructors to integrate social media into their educational settings.

3. Content types

The third dimension is content type intended for instruction, important for any decision about social media. Based on the literature were decided upon. Each content type has different advantages for students, playing an important role during instructional design. They are also important differences based on social media types, since different social media can support different content types. In the toolkit, content types are explained with sample activities that can help instructors in course design, plus additional information is available to users if required.

4. Assessment

The fourth dimension of the framework is assessment. Type of assessment has been addressed in many studies and results have indicated that types of assessment have different effects on student performance and learning. This reason was considered an important point in the decision for social media type, and so two general classification choices, Alternative Assessment, Classic Assessment, aim to match requirements of the diverse target group, although the literature also has other classifications of assessments, the first has assessments types as summative or formative. While the other has classical and alternative, since there is no common paradigm for different countries' educational systems, classical and alternative assessments were used to develop the toolkit, being the more general terms of classification [8].

The review of social media models shows that online social media usage has grown exponentially over the last decade. This growth has been driven by the Web 2.0 concept, which allows for the creation and sharing of user generated content (Hershey, 2010, p. 196). Online social media includes collaborative platforms such as wikis, blogs, and discussion boards that can be used to form virtual communities. Online social media are communication and collaboration tools found in varied arenas especially educational arenas (Mbati, 2013) [16]. The growth of technology in educational domain has evolved into a new level where all the information is communicated to the end user through a web such as e-learning environment, virtual classes, simulation tools, common web forum, etc. These infrastructural enhancements provide a valuable reason for upgrading in sharing information effectively to all users (Sathik and Venkat, 2015) [14]. Social media and social media tools represent a set of Internet based tools for sharing and discussing information' or 'activities that integrate technology and social interaction [15]. 


\section{IMPLICATIONS}

It is important to focus on how the media reaches the target group and addresses the needs of the students. To design appropriate e-learning environments and to avoid failure and dropout, it is essential to give attention to the context, characteristics, motivation, abilities, prior knowledge, experience, etc. of the learners. Therefore, learner and context analysis are the first fundamental steps in the instructional design process. Another important aspect in instructional design is to understand media behavior. It is important to focus on how the media reaches the target group and addresses the needs of the students. Understanding media usage patterns, evaluating and measuring modes of media usage is an important procedure in instructional design [17]. Use of social media is on the rise within education, both outside and inside the classroom. As more educators incorporate social media in the classroom, they have needed to seek out new and old teaching and learning theories for incorporating the technology in pedagogically meaningful ways. When incorporating any kind of media, educators must consider the construct of the course, the technologies used and the pedagogical approach to designing and delivering learning activities. With the multitude of tools and approaches available, the challenge is in finding the approach that has the most meaningful learning outcome. One approach is to encourage learners to use social media actively in their learning and research, opening up the potential for them to develop the skills they need for creating a personal learning environment and bringing them a step closer toward becoming more self directed learners [4].

Razmerita et al., (2009) (in Assegaff et al, 2016) proposes multiple technologies in social media that can be used in optimizing knowledge sharing, namely: personal webpages is a tool that can improve the organization and presentation of information and sharing, with the community. Personalized search tools provide the facility to search for and share information, Social bookmarking tool that allows community members to share bookmarks of interest among the members, personalized live discussion forum is a tool that can guide in analyzing, evaluating, displaying and sharing information among members komuintas, virtual world is a tool that encourages community members to share their knowledge, blogs and wikis are the tools and support for editing, viewing, organizing information or knowledge by individuals or collaborate with others[18].

Sathik and Venkat (2015), noted that nowadays the amount of web data stored in web servers is increasing rapidly. Online social networks, have exploded in popularity and now rival the traditional web in terms of usage. Impact of social web in educational domain reflects the magnitude of data accessed on the web for learning online. Especially in the field of open and distance learning the knowledge transferred online is huge. The social networking sites Face book, Orkut, LinkedIn and Whatsapp are examples of widely used popular networks to share the enormous amount of knowledge among the various users from which the users take the crucial decision in various domains, for example in educational domain, choosing the best institute to pursue higher studies, finding the premier and special institute to pursue research work, identifying the current requirement of corporations for the recruitment of learners, deciding on best online material available for the different class of academics and getting career guidance information [14].

\section{RESULT AND DISCUSSION}

The utilization of web-based social networking is quickly venturing into the instructive part. Pearson Learning Solutions distributes a yearly study, which demonstrates an expansion in online networking use by instructors. Every year, pearson learning Solutions puts out the consequences of a yearly overview of webbased social networking use in instruction. With the expanded utilization of mixed learning and flipped classroom procedures, the expansion of $21 \%$ over the most recent one year is not very astounding. Workforce is currently more intrigued by the capacity to use online networking to encourage engagement with course material and to support the learning procedure [19].

Alrahmi et al., (2015) pointed out that social media's potential power to facilitate higher-level learning outcomes via collaborative learning appears evident and it is supported by studies in literature. Even UNESCO, in its policy document, supported the potential of social media in this regard and recommended classroom experimentation with it to highlight its strengths and weaknesses. The perspective of the potential effective use of collaborative learning via social media in institutions of higher learning in the present time is often referred to as Web 2.0. This provides more interaction, collaborative learning, and user modifications compared to Web 1.0, which is characterized as a more static resource that allows less interaction. In comparison to normal websites, social media has specific applications that provide various ways to collaborate. They comprise different tools elaborated by Kaplan and Haenlein (2010), which include collaborative projects (Wikipedia), blogs, content communities (YouTube), and social networking sites (Facebook). Social networking sites have strong academic cultures that are built within the online community. Social media does not merely allow knowledge transfer but it also facilitates students' 
collaborative learning to creating understanding among students, discussion with peers, lecturers, increase knowledge sharing, and improve learners research skills [20].

Mukandla and Minnaar (2017), discussion focused on online collaborative learning theory which deals with educational applications that facilitate idea generation, idea organization, and intellectual convergence through the internet. So In order to facilitate idea generation, idea organization, intellectual convergence and knowledge building in e-learning, social media, and technologies are needed to facilitate collaborative interactivity in e-learning and social medid [21].

The researcher provide the following frame work for the use of social media for adult education purposes.

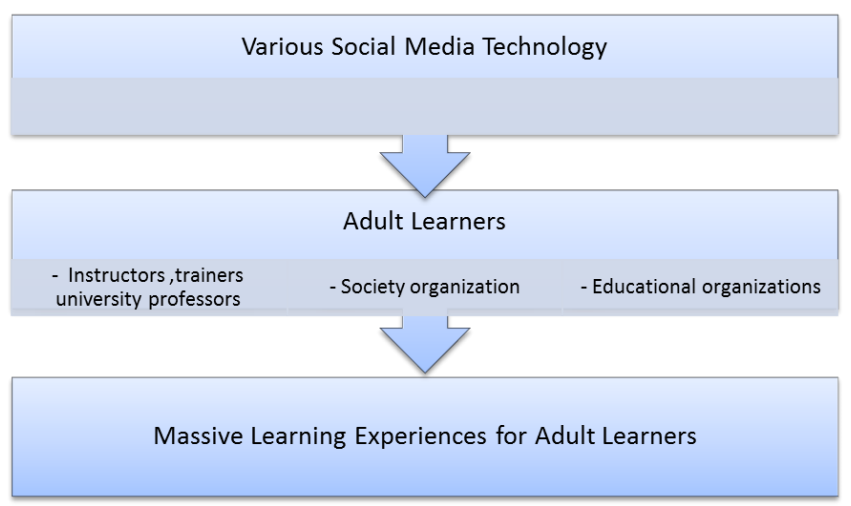

Teachers in all types of schools must also consider how the information gathering and learning that occurs in the informal learning context can be used in a learning context. Web 2.0-technology allows geographically separated learners to participate in a $21^{\text {st }}$ century classroom. Unifying factors associated with the recent web 2.0-technology are related to sharing, collaboration, networking and community. The characteristics of the content have changed to a more dynamic state, with a higher degree of participation and influence. Key pedagogical questions related to these changes in content and pattern of use is what learning competencies, knowledge and practices that develop [22].

Social networking services (SNS) are fast-growing social software which allows individuals to learn about and communicate with others easily, this class of social software allows users to work together and study collaboratively. The most popular collaborative services are Wikis, Google Docs, and Zoho, among others. They are frequently used and tested in education, and continue to be investigated in order to provide more effective usage in educational settings [23].

Salmon et al., 2015 argued that Social media in higher education has been found to enhance learning outcomes and academic achievement, and to contribute to knowledge construction. Social media can assist students to share administrative information with peers, such as meeting times and locations, and assessment requirements and also to network and promote peer feedback. When deployed for learning, social media can facilitate the development of online communities, allowing for collaborative and participatory engagement by placing emphasis on collective knowledge and social interaction. Social media can help strengthen the social relationships among students, heighten students' self-esteem, and boost their learning performance. Students may be more willing to voice their opinions or disagreement with peers in an online discussion rather than in a face-to-face setting. Further, online social interaction allows shy students to contribute and be heard by the group, and thus may provide benefits to those with lower self esteem [11]. Gulbahar et al., (2015) indicated that when used properly, social media can create effective learning environments for students, with environments they value for individual gain, whilst effective use fosters instructors' awareness of potential benefits for both instructor and learners. Their research indicated that social media as an effective learning environment, can support traditional courses. Social media makes it easier to reach students, to communicate with them at any time, both generally and beyond the confines of the classroom, and encourages peer learning, group work, and socialization among learners [9]. Aydin (2012), in Raspovovic et al., (2017), said that as students are mainly using Facebook for communication and interaction, including adaptation to new school programs and cultures, discovering social activities, finding and maintaining relationships, seeking knowledge on a variety of subjects, self-representation and self-promotion, recruitment, sharing knowledge, academic purposes, and adhering to specific agendas, findings show that using Facebook increases learners' self-efficacy, motivation, and self-esteem while reducing anxiety in the teaching and learning processes [12]. 7. CONCLUSION 
As with traditional lifelong learning there is not one ideal method for education using social media tools. Adult learners will need information in a variety of formats, designed to fit the specific educational objectives, to fit different learning style and preferences, and to fill the learner gap over time given new evidence, new opportunities, and new challenges. Methods of teaching that promote adult learner engagement are the most effective. Similarly, social media tools that engage the learner, provide accurate and up to date information, and can be easily modified to accommodate new and emerging research in specific subject areas are likely to be the most effective tools for lifelong learning [24]. The effective deployment and use of technology in educational settings can, at least to some extent, ameliorate educational and social inequalities and provide learners with access to educational resources in ways not previously possible. In resource-constrained settings where more classic digital means, such as online forums, can be unpopular and unsuccessful. The increasing adoption of social media, and in particular of social networking sites, may offer novel affordances to educate, train, and supervise learners [25]. Zornic and Hasanovic (2011) believe that the role of interaction in online learning using social media, is crucial for effective learning because it is not only learners to learners interaction that matters. Six different forms of interaction that account for learning can be recognized in distance learning education: learner learners, learners teacher, learners content, learners teacher, teacher content, and content content [12]. Tools that encourage interaction, engagement, and collaboration, such as Facebook, Twitter, and blogs are innovative tools for the classroom, and as a stepping off point to extend learning beyond pre or post the classroom. Educators found that utilizing these social media constructs led to increased learner participation as well as improved interaction with peers. There is also a potential to break down hierarchy and facilitate questions and answers among students, trainees, and faculty [24]. Kind and Evans also added that with rapid easy access and ease of information-seeking and sharing, there is also online learning at the point of care, and other formal and informal opportunities to learn and share information. Reading blogged summaries with links to the peer- reviewed literature, participating in social media based journal clubs and classroom technology that links student to professor and other experts are becoming more common asocial media becomes interdigitated with lifelong learning [25].

Chen and Bryer (2012) provided some current practices drawn from their study about using social media in formal and informal learning that could be presented in this study as suggestions and recommendations:

a. Use social media as tools to facilitate informal discussions and collaborations with clear instructional goals.

b. Understand that the focus of social media activity for some faculty is learners' personal interests and preferences, rather than institutional or instructors' requirements, evidenced by faculty, who reported both opportunities and concerns regarding their perceived obstacles to students using social media for learning purposes.

c. Evaluate students' reflections on their learning via social media in the form of formative assessment.

d. Use social media as an optional tool inside and outside classes. Provide students with alternative assignments if they choose not to participate.

e. Educate students about the security and privacy issues of posting personal information online.

f. Implement institutional policies on the use of social media in the educational environment in light of security/privacy issues, as well as faculty and student support.

g. The use of social media in higher education teaching is an emergent area study [26].

\section{REFERENCES}

[1] Le Noue, et al., "Adult Education and the Social Media Revulotion”, Adult Learning, vol. 22, no. 2, 2011.

[2] Helmi Norman, et al., "Exploring the Roles of Social Participation in Mobile Social Media Learning: A Social Network Analysis", International Review of Research in Open and Distributed Learning, vol. 16, no. 4, 2015.

[3] Shen Wen, et al., "Analysis of Social Media Influencers and Trends on Online and Mobile Learning", The International Review of Research in Open and Distributed Learning, vol. 18, no. 1, 2017.

[4] Blaschke and Lisa arie, "Using Social Media to Engage and to Develop the Online Learner in Self Determined Learning", Research in Learning Technology, vol. 22, no. 1, 2014.

[5] Feldman, Eric M., "The Influence on Social Media on Adult Learners Knowledge Construction and Democratic Participation", New Horizons in Adult Education and Human Resources Development, vol. 27, no. 4, 2015.

[6] Green Christine and Lewin Cathy, "Social Media and Education: Reconceptualizing the Boundaries of Formal and Informal Learning”, Learning Media and Technology, vol. 41, no. 1, 2016.

[7] Kear Karen, et al., "Social Technologies for Online Learning: Theoretical and Contextual Issues", Open Learning the Journal of Open Distance and E Learning, vol. 31, no. 1, 2016.

[8] Yasemin Gülbahar, et al., "Enriching Higher Education with Social Media: Development and Evaluation of a Social Media Toolkit", International Review of Research in Open and Distributed Learning, vol. 18, no. 1, 2017. 
[9] Schreurs, et al., "An Investigation into Social Learning Activities by Practitioners in Open Educational Practices", International Review of Research in Open and Distributed Learning, vol. 15, no. 4, 2014.

[10] Berlilana and Taqua Harigona, "Understanding of Antecedents to Achieve Customer Trust and Customer Intention to Purchase E-Commerce in Social Media, an Empirical Assessment", International Journal of Electrical and Computer Engineering (IJECE), vol. 7, no. 3, 2017.

[11] Salmon Gelly, et al., "The Space for Social Media in Structured Online Learning", Research in Learning Technology, vol. 23, no. 1, 2015.

[12] Raspopovic Miroslava, et al., "The Effects of Integrating Social Learning Environment with Online Learning", International Review of Research in Open and Distributed Learning, vol. 18, no. 1, 2017.

[13] Alsaadat Khalil, "Mobile Learning an Alternative Approach In Higher Education", European Journal of Alternative Studies, vol. 2, no. 1, 2017.

[14] Sathick Jbuvar and Venkat Jaya, "A Generic Framework for Extraction of Knowledge from Social Web Sources (Social Networking Websites) for an Online Recommendation System", International Review of Research in Open and Distributed Learning, vol. 16, no. 2, 2015.

[15] Thomas, et al., "Social Media Maturity Level", International Journal of Healthcare Management, vol. 9, no. 1, 2016.

[16] Mbati Lydia, "Online Social Media Applications for Constructivism and Observational Learning”, International Review of Research in Open and Distributed Learning, vol. 14, no. 5, 2013.

[17] Zawacki Olaf, et al., "Student Media Usage Patterns and Non-Traditional Learning in Higher Education", International Review of Research in Open and Distributed Learning, vol. 16, no. 2, 2015.

[18] Assgaff, et al., "Social Media Success for Knowledge Sharing: Instrument Content Validation", International Journal of Electrical and Computer Engineering, vol. 6, no. 5, 2016.

[19] Kumar, et al., "A Review of Social Media: In Future”, Indonesian Journal of Electrical Engineering and Computer Science (IJEECS), vol. 8, no. 3, 2017.

[20] Al-Rahmi, et al., "The Role of Social Media for Collaborative Learning to Improve Academic Performance of Students and Researchers in Malaysian Higher Education", International Review of Research in Open and Distributed Learning, vol. 16, no. 4, 2015.

[21] Mnkandla Ernest and Minnaar Ansie, "The Use of Social Media in E-Learning: A Metasynthesis", International Review of Research in Open and Distributed Learning, vol. 18, no. 5, 2017.

[22] Nilsen Anders Grov and Stord Gran Almas, "Added Values and Challenges Social Media Represent in the Hybridization of Teacher Training", European Journal of Open, Distance and E learning, 2016.

[23] Kilis Selcan, et al., "Exploration of Teaching Performances of Instructors Use of Social Media", European Journal of Open, Distance and E Learning, 2016.

[24] Kind, et al., "Social Media for Lifelong Learning", International Review of Psychiatry, vol. 27, no. 2, 2015.

[25] Pimmer Christoph, et al., "Supervision on Social Media: Use and Perception of Facebook as a Research Education Tool in Disadvantaged Areas", International Review of Research in Open and Distributed Learning, vol. 17, no. 5, 2016.

[26] Chen Baiyn and Bryer Thomas, "Investigating Instructional Strategies for Using Social Media in Formal and Informal Learning", International Review of Research in Open and Distributed Learning, vol. 13, no. 1, 2012. 